\title{
Yeşil Bilişim: Bir Kamu Kurumu Örneği ve Politika Önerileri
}

\author{
Green Computing: A Case Study In A State Organization And Policy \\ Recommendations
}

Yılmaz GÖKŞEN', Muhammet DAMAR², Onur DOĞAN

\begin{abstract}
ÖZET
İklim değişikliği ve küresel ısınma günümüzde insanoğlunun yüzleştiği en önemli çevre sorunlarından biridir. Dünyamız, küresel ısınma ve iklim değişikliğinin olumsuz etkileri ile her geçen gün daha şiddetli yüzleşmektedir. Doğal kaynaklarımız bu şekilde tüketilirse, gezegenimizin orta ve uzun vadede intiyaca cevap veremeyeceği tahmin edilmektedir. Bu nedenle, tedbir almak, iş yapış şekillerimizi değiştirmek, doğaya olumsuz etkimizi minimize etmek, önemli bir unsur haline gelmektedir. Bilişim teknolojileri, bu zorlu sorunun çözümündeki anahtar unsur olarak karşımıza çıkmaktadır. Bilgi ve iletişim teknolojileri, küresel ısınma, iklim değişikliği, sanayi atıkları gibi çevresel tehditler için en önemli mücadele aracı olarak karşımıza çıkmaktadır. Türkiye'de kamu kurumları, enerji tüketimi, teknolojik ürünlerin satın alınması, kullanımı, süreçlerin iyileştirilmesi adına önemli bir potansiyele sahiptir. Çalışma, kamu bilgi işlem birimlerinin bilgi işlem süreçlerini, yeşil bilişim yaklaşımıyla ele alarak, politika önerileri ortaya koymayı amaçlamıştı. Çalışmada, örnek bir kamu bilgi işlem biriminin sahip olduğu bilgi sistemleri ve teknoloji ile altyapısının bir envanteri çıkarılacaktır. Bu envanterin hâkim elemanlarının muhtemel çevresel etkileri, sistematik bir şekilde değerlendirilecektir. Kamu çalışanlarının yeşil bilgi işlem algısı, kurum içi yeşil bilişim politikası, iletişim teknoloji araçlarııın satın alınması, geri dönüşümü, laboratuvarlarının tasarımı, enerji tüketimi, projelerin sanallaştırılması, sunucu odalarının durumu, yeşil üniversite ve kurumlar konusunda yapılabilecekler, literatür çerçevesinde Türkiye'den ve Dünya'dan örnekler ile ortaya konulacaktır. Çalışmanın yeşil bilişim konusunda bireysel ve örgütsel farkındalığı artırması, yeşil bilişim gibi önemli bir konunun yukarıda vurgulanan konular temelinde ele alması açısından önemli olduğu düşünülmektedir.
\end{abstract}

Anahtar Kelimeler: Enerji, Enerji Tasarruf, Yeşil Bilişim, Bilgi Teknolojisi, Kamu Kurumu.

\begin{abstract}
Climate change and global warming is one of the most important environmental problems that mankind faces today. Our world today faces negative effects caused by global warming and global climate change more intensely. If our natural resources are consumed as it is today, it is estimated that our planet will not suffice in the mid and long run. That's why taking necessary measures, changing our way of doing our work and minimizing our negative effects of ours to nature have been important elements. At this point, information technologies emerge as a key element in solving this crucial problem. Information and communication technologies now emerge as fighting tools against environmental threats like global warming, climate change and industrial waste. In Turkey, public institutions have a significant potential from the point of view of energy consumption, purchase of technological products, their usage and the improving the processes. This study aims at handling the public information processing units' information processing with green IT approach and making suggestions. In this study, the inventory of the information systems, technology and infrastructure that a sample public information processing units has will be taken. The likely environmental impact of the inventory of the prevalent element will be evaluated in a systematic way. Samples from Turkey and the world will be discussed according to the following subjects such as green computing perception, green computing policy in the organization, purchasing of communication technology tools, recycling, rational design of the laboratories, energy consumption, virtualization of projects, server room preferences and their location, green university, and what can be done about green organizations. This study is thought to be important from the point of view of handling green computing considering the factors mentioned above and increasing the personal and organizational awareness.
\end{abstract}

Keywords: Energy, Saving Energy, Green Computing, IT, Public Statement. 


\section{GíRiş}

İklim değişikliği ve küresel ısınma, içinde bulunduğumuz çağda insanoğlu kaynaklı ve insanoğlunun yüzleşmek zorunda kaldığı en önemli çevre sorunlarından birisidir. Doğal kaynakların hızla tüketimi ve doğanın dengesinin bozulması buna en büyük nedendir. Tema Vakfı (2015)'na göre, insanlığın tüketim anlayışı değişmeksizin devam ederse, 2030 yılında gelindiğinde intiyaçların karşılanması için iki, 2050 yılına gelindiğinde ise üç dünyaya intiyacımız olacaktır. Bu nedenle, tedbir almak, iş yapış şekillerimizi değiştirmek, doğaya olan olumsuz etkimizi minimize etmek gerekmektedir.

Türkiye'nin Ekolojik Ayak İzi Raporu (2012)'na göre, Türkiye'de kişi başına düşen tüketimin 2007 yılındaki ekolojik ayak izi 2.7 kha'dır. Bu durum dünya ortalamasının \%50 üzerindedir. Diğer bir ifadeyle açıklamak gerekirse, dünyadaki diğer insanlar ortalama bir Türk vatandaşı kadar tüketim yaparsa, 1.5 gezegene ihtiyacımız olacaktır. Bu bağlamda bilişim sektörünün dönüştürücü etkisi karşımıza fırsat olarak çıkmaktadır. Sektör, sınırlı olan doğal kaynakların tüketimini azaltarak, aynı miktarda ürünü daha az enerji ve kaynak tüketerek elde edebilmektedir. Örneğin; bilişim teknolojileri vasıtasıyla geliştirilecek e-evrak takibi ile kurum içi kağıt tüketimi, çok daha düşük seviyelere çekilebilmektedir. Geliştirilen sistem sadece kağıt tasarrufu değil, iş süreçlerinin etkinleştirilmesi, süreçlerin kayıt altına alınması ile veri kaybını önleme ve düşük arşiv maliyeti gibi faydalar sağlayabilmektedir.

BölgeselÇevreMerkezi'nin SürdürülebilirKalkınma İ̧̧in Bilişim Raporu (2013)'na göre, bilişim sektörünün sera gazı azaltma potansiyeli, kendi karbon ayak izinden yedi kat fazladır. Bilgi ve iletişim teknolojileri, küresel ısınma, iklimsel değişiklikler, sanayi kaynaklı atıklar gibi çevresel tehditler ile mücadele aracı olarak karşımıza çıkmaktadır. Türkiye'de kamu kurumları, enerji tüketimi, teknolojik ürünlerin satın alınması, kullanımı, süreçlerin iyileştirilmesi adına önemli bir potansiyele sahiptir. Bu noktada, Dokuz Eylül Üniversitesi Sosyal Bilimler Enstitüsü (DEÜSBE) çalışma sahası olarak belirlenmiştir. Kurumun bilgi işlem süreçleri analiz edilecek, harcanan enerji miktarı ile kullanıcı alışkanlıklarına bağlı tüketim maliyetleri ortaya konulacaktır. Enerji etkinliği, bütçenin etkin kullanımı, çevreye ve insan sağlığına duyarlı olmak gibi hedefleri olan yeşil bilgi işlem yaklaşımı ile Türkiye'deki kamu kurumlarına önerilerde bulunulacaktır. Çalışma, kurumdaki bilişim teknolojilerinin enerji sarfiyatlarını, kullanıcıların cihaz kullanım alışkanlıklarını ortaya koymakta ve bilişim araçlarının kullanıcı alışkanlıklarına bağlı maliyetlerini ortaya koymaktadır.

\section{KAVRAMSAL ÇERÇEVE VE LITERATÜR}

Son yıllarda artan çevre sorunları nedeniyle, üretim ve tüketimin sürdürülebilirliği üzerine çok sayıda çalışma yapılmaktadır. Bu bağlamda, kamu ve özel kuruluşlar, çevreye dönük sorumluluk projelerine imza atmakta ve süreçlerini daha çevreci yeniden tasarlamaktadırlar. Kurumlar, çevreci politikaların ve girişimlerin önemini fark etmiştir. Akademik olarak çalışılan yeşil pazarlama, yeşil tedarik zinciri, yeşil üretim, yeşil bilişim gibi kavramlar organizasyonlar içinde içselleştirilmeye çalışılmaktadır.

Yeşil bilişim, bilgisayar kaynaklarının uygulamada etkin bir şekilde kullanımını ifade etmektedir (Chakraborty vd., 2009). Yeşil teknoloji olarak da adlandırılan yeşil bilişim; çevresel sürdürülebilirlik adına, bilgisayar ve bilgisayarlar ile ilişkili monitör, yazıcı, depolama araçları ile ağ ve iletişim sistemleri gibi kaynakların, çevreye en az zarar verecek biçimde etkin ve verimli kullanılmasıdır (Shinde, Nalawade ve Nalawade, 2013). Yeşil bilişim, bilgisayar ve bilgisayarlar ile ilgili kaynakların çevresel sorumluluk bilinciyle kullanımı olarak da ifade edilmektedir (Aggarwal, Garg ve Kumar, 2012). Yeşil bilişim, bilişim ürün ve hizmetlerinin çevreye duyarlı ve doğanın zarar görmeden üretilmesi, kullanılması ya da kullanım sonrası faaliyetlerin çevresel olarak sürdürülebilir olması anlamına gelmektedir (BTK, 2010).

Özetle yeşil bilişim, bilişim teknolojilerinin çevreye duyarlı tasarımını, üretimini ve dağıtımını ifade ettiği gibi; kullanım ömrü tamamlandıktan sonra, cihazların doğaya zarar vermeden dönüştürülmesi anlamına gelmektedir. Elektrikli ve elektronik cihazlar, birçok zararlı bileşen intiva ettiklerinden ötürü, doğru bir şekilde geri dönüştürülmediklerinde, insan sağlığı ve çevre olumsuz etkilenmektedir. Gaz salınımı ve atık imhası açısından firmalardaki birçok uygulama akademik yayınlara konu olmuştur. Örneğin, Hart ve Ahuja (1996) çalışmalarında; gaz emisyonundaki azaltmaya yönelik faaliyetlere harcanacak maliyetin, firma performansına olumlu etki oluşturduğu ve yatırım maliyetini karşıladığını göstermiştir. Akın ve Kuru (2011) ülkemizde hızla artan elektronik atıkların (e-atık), emniyetli ve güvenli şekilde toplama, yok etme ve geri dönüşüm işlemlerinin bir sektör haline dönüşmesi gerektiğini savunmaktadır. Bu 
bağlamda Dünya'da e-atıkla ilgili kanuni yaptırımları; üreticinin ürününü geri alması, ön ödemeli geri dönüşüm ücreti alınması ve vergi kredisi koyması olduğunu vurgulamışlardır. Hepkul ve Polatoğlu (2013), işletmelerde kurumsal sosyal sorumluluk kapsamında, e-atıkların yok edilmesi ile ilgili çalışmalarında, e-atık ifadesinin kavramsal alt yapısı ile ilgili bilgi paylaşımında bulunmuşlardır. Aynı zamanda çalışmalarında, Türkiye'de ve Dünya'da e-atık konusunu üstesinden gelinmesi gereken bir zorluk olarak ele almakta, zorlukla başa çıkmak için hükümetlerin daha fazla yasal düzenlemeler getirmesi gerektiğini vurgulamaktadırlar. Yazıcı ve Deveci (2011) elektronik atıkları, geleceğin madenleri olarak görmektedirler. Örneğin; altın yatağından çıkarılan 1 ton cevherden yalnızca 5 gram altın elde edilebiliyorken, cep telefonundan çıkarılan yapay cevherden edinilen altın 150 gramdır. Japonya bu noktada ulusal politikalar üretmekte ve bu alanda araştırma enstitüleri (Materyal Bilimleri Ulusal Enstitüsü) kurmaktadır (Dünya Gazetesi, 2010).

Bose ve Luo (2011), yeşil bilişim kavramının, yönetim bilişim sistemleri alanında, çalışmaya açık ve aktif bir alan olduğu vurgusunu yapmışlardır. Araştırmacılara göre temel eksiklik, yeşil bilişim alanında teorik çerçevenin oluşmamış olmasıdır ve çalışmalarında bu eksikliği gidermeyi, organizasyonların yeşil bilişim hazırlıklarına ilişkin tanımlayarak örneklerde bulunmayı hedeflemişlerdir. Jenkin, Webster ve McShane (2011) çalışmalarında; yeşil bilişim ve yeşil sistemler kavramlarının sürdürülebilir çevre için oldukça hayati kavramlar olmalarına rağmen bu konu hakkında çok az çalışma yapıldığına dikkat çekerek, sonraki çalışmalara yardımcı olmak için literatür çerçevesi çizmişlerdir. Molla, Cooper ve Pittayachawan (2009) yeşil bilgi teknolojilerine hazır olma (G-Readiness) kavramına ait model önerilerini, Avustralya, Yeni Zelanda ve ABD'de işverenlere yaptıkları anket çalışmasıyla sunmuşlardır. Yeşil bilgi teknolojilerine hazır olma modeli; yeşil bilgi teknolojileri, yeşil bilgi teknolojileri davranışları, yeşil bilgi teknolojileri politikaları, yeşil bilgi teknolojileri uygulamaları olmak üzere alt bileşenlerden oluşmaktadır.Elliot ve Binney (2008)'e göre işletmenin tüm süreçlerinde bilgi teknolojileri birleştiricidir ve bilgi teknolojilerinin yaşam döngüsünde çevreye zararlı etkilere söz konusudur. Andreopoulou (2012), yeşil bilişimi, üretim sırasında enerji tüketimi ve karbon ayak izinin azaltılması, çevresel duyarlılık ve farkındalığın eğitim ile arttırıması, çevre projeleri konusunda etkili iletişimin kurulması, sürdürülebilir çevre yönetimine sahip olunması olmak üzere dört boyuttan oluştuğunu belirtmişlerdir. Dao, Langella ve Carbo (2011) çalışmalarında, bilgi teknolojileri alanındaki sürdürülebilirliğingenellikleenerji tüketimi üzerine yoğunlaştığının altını çizerek gerçekte, yeşil bilişim kavramının bunun çok ötesinde bir kavram olduğunu belirtmişlerdir. Bengtsson ve Agerfalk (2011) çalışmalarında, organizasyonlarda yeşil bilişim uygulama sürecini, İsveç'te bir şehirde yaptıkları inceleme ile mercek altına almışlardır. Çalışmada, yeşil bilişism uygulamalarına kurumlarda gösterilen direncin, genellikle organizasyonel seviyede yaşandığı ve geçmiş yapının bozulmasına yönelik bir direnç ile karşılaşıldığına dikkat çekmişlerdir.

Özdemir, Naralan ve Çam (2015) sanallaştırma teknolojisi, organizasyonlara esneklik ve ölçeklenebilirlik kazandırırken, organizasyonlara rekabet üstünlüğü sağlamada fırsatlar sunduğunu belirtmişlerdir. Sanallaştırma teknolojisi ile bilgi işlem altyapılarının; yönetim, işletme ve bakım maliyetlerinin önemli ölçüde azaldığını, organizasyonların \%70'lere varan bir maliyet tasarrufu sağladığını belirtmişlerdir. Çetin ve Akgün (2015) sanallaştırma teknolojisi ve klasik sistemle oluşturulmuş iki labratuvarları kıyasladıkları çalışmalarında; sanal sistemi, çevreci ve maliyet düşürücü olarak ifade etmişlerdir. Klasik sistemle donatılmış laboratuvar 3790w enerji harcarken, aynı koşullarda sanallaştııımış laboratuvardaki sistemin 720w enerji harcadığını tespit etmişlerdir. İki laboratuvar arasındaki maliyet farkı aylık (22 gün) 216 TL'dir.

Chou (2013) çalışmasında; yeşil bilişim uygulamalarının sonuçlarını etkileyebilecek risk faktörlerini ele almıştır. Chou ve Chou (2012) çalışmalarında, sürdürülebilir çevreye katkı verecek yeşil bilişimin değerini, bir model ile izah etmişlerdir. Onlara göre, model, süreci farkında olma ile başlar, dönüşüm, anlama ve yeşil bilişim değerini ortaya koyma olarak sıra ile devam eder ve yeşil bilişim değeri sürdürülebilir çevreye katkıda bulunur. Kamu kurumlarında, yeşil bilişim, yeşil tedarik zinciri vb. faaliyetlerin entegre edilmesine yönelik çalışmalar literatürde yer almaktadır. Bu çalışmalardan birisi, Zhu ve Cote (2004) tarafından yapılan, bir devlet kuruluşu olan Guitan Group adlı kuruluşa yeşil tedarik zincirinin entegre edildiği ve bulgular üzerine çözüm önerilerinin ortaya konulduğu çalışmadır. 


\section{UYGULAMA}

Çalışmada örnek bir kamu bilgi işlem biriminin sahip olduğu bilişim sistemleri ve donanım altyapısı yeşil bilişim odağında, kullanıcı alışkanlıklarıyla beraber analiz edilmektedir.

\subsection{Amaç}

Uygulama; örnek bir kamu birimini ele alarak, çalışanların yeşil bilgi işlem algısını, kullanıcı alışkanlıklarını, teknoloji araçlarının kullanım şekillerini, kurum ve kullanıı bazında ortaya koymayı amaçlamaktadır. İlgili birim sorumlularını kapsayan "Birim Sorumlusu GörüşmeFormu"(BSGF)ilekullanılan bilişim teknolojisi, cihazlarının satın alınma süreçleri, geri dönüşümü ve uygulamalar gibi bir çok konuda tanımlayıcı veriler toplanmıştır. Kullanılan bilişim cihazlarının enerji tüketim maliyetleri hesaplanmış, "Kullanıcı Görüşme Formu" (KGF) ile kullanıcı cihaz kullanım alışkanlıkları ortaya konulmuştur. Bu sayade kuruma yansıyan kullanıcı alışkanlıklarına bağlı maliyetlerin bulunması hedeflenmiştir.

\subsection{Kapsam ve Yöntem}

Çalışmada yöntem olarak bir vaka gerçekleştirilmiştir ve DEÜSBE yeşil bilişim açısından mercek altına alınmıştır. Bu bağlamda, DEM 1499 ölçüm cihazıyla enerji sarfiyatı üzerine ölçümler yapılmasının yanında, birim yetkilileri için BSGF ve birim çalışanları için KGF olmak üzere üç aşamalı bir yöntem uygulanmıştır. Bu kapsamda izlenen adımlar sırasıyla aşağıda açıklanmaktadır.

\subsubsection{Elektronik Enerji Ölçüm Cihazı Ille Hesaplamalar}

Kullanılan cihaz; DEM 1499 elektronik enerji ölçüm cihazıdır (Şekil 1). Bu araç vasıtasıyla cihazların enerji tüketimleri ölçülebilmiştir. Kullanılan cihazların oluşturabileceği maliyet saatlik tüketime göre hesaplanmaktadır. İlgili cihazlar Tablo 1 üzerinde gruplandırılmış ve sayıları verilmiştir.

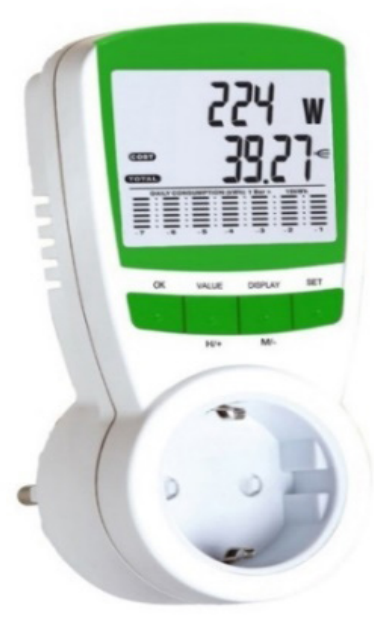

Şekil 1: Enerji Tüketimini Ölçmek İçin Kullanılan Cihazın Görüntüsü

Elbette bilişim teknolojisinde kullanılan bir çok cihaz vardır. Bu noktada, Tablo 1 üzerindeki cihazlar, DEÜSBE'de yapılan gözlem sonucu mantıksal olarak gruplanmıştır.

Tablo 1: Bilişim Cihazları

\begin{tabular}{|c|c|c|c|}
\hline Cihaz Türü & Sayı & Cihaz Türü & Sayı \\
\hline Masaüstü Bilgisayarlar & 74 & Tarayıcı & 3 \\
\hline Tüplü (CRT) Monitörler & 12 & Dizüstü Bilgisayarlar & 15 \\
\hline Kasasız Bilgisayarlar (all in one) & 55 & Yazıcı & 76 \\
\hline LCD Monitörler & 55 & Faks Makinası & 1 \\
\hline Hoparlör (Speaker) & 20 & Fotokopi Makinası & 7 \\
\hline Dizüstü Bilgisayarlar & 15 & Televizyon & 3 \\
\hline YazıCı & 76 & Projeksiyon Cihazı & 27 \\
\hline
\end{tabular}

\subsubsection{Birim Sorumlusu Görüşme Formu}

Kurumda uygulanan ilk form BSGF'dir. Form, birim sorumlusuna, yeşil bilişim hakkında bilgilendirme yapıldıktan sonra uygulanır. Birim sorumlusuna sorulan sorular kurum hakkında bilişim teknolojilerinin kullanımı, laboratuvar sayısı, kurumun kullandığı bilişim teknolojileri vb. genel ve tanımlayıcı bilgileri içermektedir (Tablo 2). Sistematik olarak bilişim sistemlerinin durumunu ortaya koymak ve envanter çıkarmak hedeflenmektedir. 
Tablo 2: Yetkili Görüşme Formu Soru İçerikleri

\begin{tabular}{|l|l|}
\hline Soru Kodu & Soru Metni \\
\hline Y1 & Biriminizde aylık enerji gideri miktarı (tı/kw saat) nedir? \\
\hline Y2 & Biriminizde istihdam edilen personel sayısı nedir? \\
\hline Y3 & Biriminizde evrak takip programı kullanılmakta mı? \\
\hline Y4 & Biriminizdeki ilgili cihazların sayısı nedir? \\
\hline Y5 & Kullanılan bilişim cihazları için bir geri dönüşüm çalışmanız mevcut mu? \\
\hline Y6 & Kurumunuz çalışanlarınız için teknoloji ürünleri değişim politikanız mevcut mu? \\
\hline Y7 & Kurumunuzun bir enerji politikası mevcut mu? \\
\hline Y8 & Biriminize ait toplantı odalarındaki bilişim teknolojisi cihaz sayınız nedir? \\
\hline Y9 & Biriminize ait laboratuvardaki bilişim teknolojisi cihaz sayınız nedir? \\
\hline Y10 & Biriminizdeki sunucu odası ve sunucu cihazları hakkında bilgi verir misiniz? \\
\hline Y11 & Sunucu odası kaçıncı katta yer almaktadır? \\
\hline Y12 & Sunucuları ne tür amaçlar için kullanmaktasınız ve donanım üzerinde hizmet \\
\hline Y13 & veren sistemlerin durumu hakkında bilgi verir misiniz? \\
\hline Y14 & Bulut bilişim hakkında bilginiz var mı? \\
\hline
\end{tabular}

\subsubsection{Kullanıcılara Görüşme Formu}

KGF, toplamda 3 boyuttan meydana gelmektedir ve Tablo 3'de belirtilen sorulardan oluşmaktadır.
Boyutlar; demografik özellikler, alışkanlıklar ve değerlendirme şeklindedir. Kullanıcılara form uygulanmadan önce yapılan çalışma hakkında bilgi verilmiştir.

Tablo 3: Kullanıcı Görüşme Formu Soru İçerikleri

\begin{tabular}{|l|l|}
\hline No & Soru Metni ve Boyutları \\
\hline A & Demografik Bilgiler \\
\hline 1 & Cinsiyetiniz? \\
\hline 2 & Eğitim durumunuz? \\
\hline 3 & Yaşınız? \\
\hline 4 & Kurumdaki hizmet yılınız? \\
\hline 5 & Kadro durumunuz? \\
\hline B & Kullanıcı Alışkanlıkları \\
\hline 1 & Günde kaç sayfa çıktı alırsınız? \\
\hline 2 & Çıktı alırken arkalı̈ önlü mü alırsınız? \\
\hline 3 & Kullandığınız yazıcıları iş çıkışında kapatır mısınız? \\
\hline 4 & Yazıcılarınız hafta sonları kapalı durumda mıdır? \\
\hline 5 & Bilgisayarınızı düşük enerji tüketiminde mi kullanırsınız? \\
\hline 6 & Öğle yemeğine çıkarken bilgisayarınızın durumu nedir? \\
\hline 7 & Küçük molalara çıkarken bilgisayarınızın durumu nedir? \\
\hline 8 & Kaç yıldır bilgisayar kullanıyorsunuz? \\
\hline 9 & İş yerinde günde ortalama kaç saat bilgisayar kullanıyorsunuz? \\
\hline 10 & İş yerinde günde ortalama kaç saat monitörünüz açık kalmaktadır? \\
\hline C & Değerlendirme \\
\hline 1 & Kendinize yeşil bilişim konusunda bir puan verir misiniz? \\
\hline 2 & İş arkadaşlarınıza yeşil bilişim konusunda bir puan verir misiniz? \\
\hline 3 & Kurumunuza yeşil bilişim konusunda bir puan verir misiniz? \\
\hline
\end{tabular}

KGF'den elde edilen veriler, SPSS 21 istatiksel programında analiz edilmiştir. Frekans ve yüzde ile tanımlayıcı özellikler değerlendirilmiştir. 


\subsection{Bulgular}

Yapılan çalışma üç aşamalıdır. Tablo 1 üzerindeki cihazların elektrik sarfiyatlarının hesaplanması, BSGF'nin ve KGF'nin uygulanması ile bulguların paylaşılması şeklindedir.

\subsubsection{Elektronik Enerji Ölçüm Cihazı İle Hesaplamalar}

Kurum içindeki bilişim hizmetlerinde kullanılan cihazların enerji tüketimi, enerji ölçüm cihazı ile hesaplanmıştır. $1 \mathrm{KWh}$ tüketim için maliyet 0.32 Türk Lirası (TL) olarak alınmıştır. Kullanılan cihaz türleri ve cihaz sayısı Tablo 1 üzerinde gösterilmiştir. Tablo 4 üzerinde belirlenen cihazlar için olası konfigürasyolarda ve olası senaryolara bağlı 1 TL tablosu ortaya konulmuştur. Tablo üzerinde; konfigürasyon açıklaması, cihaz modeli, saatliklik elektrik tüketimi ve 1 TL ile konfigürasyonun çalıştırılabileceği yaklaşık değerleler gösterilmiştir. Tabloda faks cihazı ve hoparlör düşük enerji tüketimi nedeniyle yer almamıştır.

Tablo 4: Belirlenen Bilişim Teknoloji Cihazları l̇çin 1 TL Tablosu

\begin{tabular}{|c|c|c|c|}
\hline Cihaz Türleri & Cihazın Modeli & $\begin{array}{l}\text { Saatlik } \\
\text { Tüketim } \\
\text { (KWh) }\end{array}$ & 1 TL ile Yapılabilecek \\
\hline $\begin{array}{l}\text { LCD monitörlü } \\
\text { masaüstü } \\
\text { bilgisayar }\end{array}$ & $\begin{array}{l}\text { Samsung syncmaster } \\
932 \text { Gw monitör ve } \\
\text { bilgisayar kasası }\end{array}$ & 0.1 & $\begin{array}{l}\text { Bir öğrenci } 31 \text { saat enstitü laboratuvarında } \\
\text { bilgisayar kullanabilir. }\end{array}$ \\
\hline Monitörsüz kasa & $\begin{array}{l}\text { Asus marka intel i5 } 3470 \\
\text { işlemci } 3.2 \mathrm{Ghz} \text { kasa }\end{array}$ & 0.06 & $\begin{array}{l}52 \text { saat boyunca bilgisayar kasası } \\
\text { çalıştırılabilir. }\end{array}$ \\
\hline Monitörsüz kasa & $\begin{array}{l}\text { Asus marka intel i5 } 3470 \\
\text { bekleme modunda kasa }\end{array}$ & 0.016 & $\begin{array}{l}195 \text { saat bilgisayar kasası bekleme modunda } \\
\text { kalabilir. }\end{array}$ \\
\hline $\begin{array}{l}\text { Dizüstü } \\
\text { bilgisayar }\end{array}$ & Acer aspire $5745 \mathrm{G}$ & 0.03 & $\begin{array}{l}\text { Dizüstü bilgisayarınız } 104 \text { saat ve } 13 \text { iş günü } \\
\text { boyunca kullanılabilir. }\end{array}$ \\
\hline $\begin{array}{l}\text { Kasasız bilgisayarlar } \\
\text { (All in one) }\end{array}$ & Hp touchsmart elite 7320 & 0.04 & $\begin{array}{l}78 \text { saat yaklaşık ve yaklaşık } 10 \text { iş günü } \\
\text { boyunca bilgisayarınız kullanılabilir. }\end{array}$ \\
\hline $\begin{array}{l}\text { Düz ekran monitör } \\
\text { (LCD) }\end{array}$ & $\begin{array}{l}\text { Samsung syncmaster } \\
932 \mathrm{GW}\end{array}$ & 0.027 & $\begin{array}{l}115 \text { saat boyunca monitörü açık kalabilir. } 14 \text { iş̧ } \\
\text { günü monitör aktif kullanılabilir. }\end{array}$ \\
\hline $\begin{array}{l}\text { Düz ekran monitör } \\
\text { (LCD) }\end{array}$ & Philips brilliance 220B & 0.017 & $\begin{array}{l}183 \text { saat boyunca, yaklaşık } 23 \text { iş günü monitör } \\
\text { aktif kullanılabilir. }\end{array}$ \\
\hline Projeksiyon cihazı & Viewsonic Vs3304 & 0.19 & $\begin{array}{l}16 \text { saat toplantı sırasında projeksiyon cihazı } \\
\text { kullanılabilir. }\end{array}$ \\
\hline $\begin{array}{l}\text { Monitörsüz kasa ve } \\
\text { projeksiyon cihazı }\end{array}$ & $\begin{array}{l}\text { Asus intel i5 } 3470 \text { kasa } \\
\text { ve Vs3304 projeksiyon } \\
\text { cihazı }\end{array}$ & 0.25 & $\begin{array}{l}12.5 \text { saat boyunca bilgisayar ve projeksiyon } \\
\text { cihazı kullanarak toplantı yapılabilir. }\end{array}$ \\
\hline Yazıcı & Canon isensy 3460 & 0.007 & 18 gün 7/24 yazıcı açık kalabilir. \\
\hline Fotokopi makinası & Triumph adler $256 \mathrm{i}$ & 0.04 & Cihaz 78 saat, 9.7 iş günü hizmet verebilir. \\
\hline LCD televizyon & Samsung UE40D5000 & 0.072 & 43.4 saat boyunca televizyon izlenilebilir. \\
\hline
\end{tabular}

\subsubsection{Yetkili Görüşme Formu'nun Değerlendirilmesi}

Kurumda yapılan yetkili görüşmesi sonucunda, DEÜSBE'nin bulunduğu bina için tek bir saatin olmadığı, binanın paylaşıldığı görülmüştür. DEÜSBE ve Dokuz Eylül Üniversitesi Denizcilik Fakültesi elektrik giderleri aynı saatten ölçülmektedir. Bu durum, bilişim teknolojileri ürünlerinin, toplam enerji giderleri içindeki yerini göstermekte bir kısıt oluşturmaktadır. Bu kısıtlayıcı durumun giderilmesi için kampüs elektrik sorumluları ile 02.08.2015 tarihinde bir görüşme yapılmıştır. Görüşme sonunda, kampüs içinde tek bir faturanın olduğu belirtilmiştir. Kampüsteki binalarda bulunan sayaçlardan okunan değerlere göre elektrik maliyeti hesaplanmaktadır. Tablo 5'de aylara göre Tınaztepe Kampüsü'ndeki birimlerin elektrik sarfiyatı ve maliyeti gösterilmektedir. 
Tablo 5: Tınaztepe Kampüsü Birimlere Göre Aylık Elektrik Maliyeti

\begin{tabular}{|c|c|c|c|c|}
\hline \multirow{2}{*}{ Birimler } & \multicolumn{4}{|c|}{ Aylık Tüketim Giderleri } \\
\hline & Nisan & Mayıs & Haziran & Temmuz \\
\hline Denizcilik Fakültesi ve Sosyal Bilimler Enstitüsü & $3236.41 \mathrm{TL}$ & 3542.11 TL & 3496.22 TL & $3786.95 \mathrm{TL}$ \\
\hline Mimarlık Fakültesi & 1539.27 TL & 1219.51 TL & $1465,15 \mathrm{TL}$ & $1633.85 \mathrm{TL}$ \\
\hline İşletme Fakültesi & 2334.25 TL & 2675.77 TL & $2726,04 \mathrm{TL}$ & 3301.54 TL \\
\hline Merkez Kütüphane & $4413.52 \mathrm{TL}$ & $3970.31 \mathrm{TL}$ & 8674.32 TL & 7613.00 TL \\
\hline Depark & 10196.50 TL & 9664.96 TL & $11703.05 \mathrm{TL}$ & $11802.66 \mathrm{TL}$ \\
\hline Serpen Kantin (Mühendislik) & 978.33 TL & 873.25 TL & $785.51 \mathrm{TL}$ & $567.55 \mathrm{TL}$ \\
\hline Kampüs Özel Aboneler Toplam & $26814.75 \mathrm{TL}$ & $26309.40 \mathrm{TL}$ & $22287.35 \mathrm{TL}$ & $20675.99 \mathrm{TL}$ \\
\hline Kampüs Resmi Binalar Toplam & $59811.95 \mathrm{TL}$ & $51771.60 \mathrm{TL}$ & $64051.05 \mathrm{TL}$ & 82773.21 TL \\
\hline Kampüs Genel Toplam & 86626.70 TL & $78081.00 \mathrm{TL}$ & 86338.40 TL & 103449.20 TL \\
\hline Aylara Göre Sabit (1 KWh = TL) & $0.310 \mathrm{TL}$ & $0.310 \mathrm{TL}$ & $0.310 \mathrm{TL}$ & $0.315 \mathrm{TL}$ \\
\hline
\end{tabular}

Tüketilen $1 \mathrm{KWh}$ enerji için ödenen miktar aylara göre değişmektedir. Kurum 1KWh için 0.31-0.32 TL aralığında ödeme yapmaktadır. Çalışmada, maliyet hesaplarında 1KWh için $0.32 \mathrm{TL}$ alınacaktır. Birim YGF'nin uygulanması sonrasında alınan cevaplar Tablo 6 üzerinde özetlenmiştir.

Tablo 6: Birim Sorumlusu Görüşme Formunun Soru Bazlı Sonuçları

\begin{tabular}{|c|c|}
\hline $\begin{array}{l}\text { İlgili } \\
\text { Soru }\end{array}$ & Görüşme Sonrası Verilen Cevap \\
\hline Y1 & $1 \mathrm{KWh}$ bir tüketim için $0.32 \mathrm{TL}$ alınacaktır. \\
\hline Y2 & Birimde aktif görev yapan 28 idari ve 11 akademik personel bulunmaktadır. \\
\hline Y3 & Tüm idari ve akademik görevliler bir bilgisayara sahiptir. \\
\hline Y4 & $\begin{array}{l}\text { Birimde evrak yönetim sistemi yazılımı bulunmamaktadır. File Maker adında, Macintosh ve Windows işletim sis- } \\
\text { temlerinde çalışabilen bir veri tabanı programlama aracı kullanmaktadır. Bu program sayesinde, öğrenci tezleri } \\
\text { arşivlenip kayıt altına alınmaktadır. }\end{array}$ \\
\hline Y5 & $\begin{array}{l}\text { Cihazlar için bir ayniyat programı bulunmamaktadır. Bu nedenle envanter oluşturabilmek için, odaların gezilme- } \\
\text { si ve birim faaliyetindeki cihazların kayıt altına alınması gerekmiştir. }\end{array}$ \\
\hline Y6 & $\begin{array}{l}\text { Kullanım ömrü biten cihazlar, Makina ve Kimya Endüstrisi Kurumuna teslim edilmektedir. Kullanım ömrü bitme- } \\
\text { miş, fakat performans olarak birim ihtiyaçlarını karşılamayan cihazlar, ihtiyacı olan okullara bağış(hibe) olarak } \\
\text { verilmektedir. }\end{array}$ \\
\hline Y7 & $\begin{array}{l}\text { Kurum, personelin bilişim teknolojilerinden etkin faydalanabilmesi için teknoloji ürünleri değişim politikasına } \\
\text { ve cihazlar için çevreci satın alma politikasına sahip değildir. İhtiyaca dönük, denetimsiz cihaz kullanım süreci } \\
\text { yürütülmektedir. }\end{array}$ \\
\hline Y8 & Kurumda aktif bir enerji politikası mevcut değildir ve bu yönde bir çalışma yapılmamıştır. \\
\hline Y9 & $\begin{array}{l}\text { Birime ait; } 2 \text { adet toplantı odası, } 3 \text { adet derslik, } 1 \text { doktora tez savunma odası mevcuttur. Toplantı odaları ve ders- } \\
\text { liklerde monitörsüz bilgisayar kasası (1) ile çevre birimleri, projeksiyon cihazı (1), hoparlör (1) mevcuttur. }\end{array}$ \\
\hline Y10 & $\begin{array}{l}\text { Birimde } 40 \text { adet masaüstü bilgisayardan oluşan bir laboratuvar bulunmaktadır. Bilgisayarların kasa konfigüras- } \\
\text { yonlarında ve monitörlerinde belirli bir standart mevcut değildir. Fakat monitörlerin tamamı LCD monitördür. }\end{array}$ \\
\hline Y11 & $\begin{array}{l}\text { Birimde } 1 \text { adet sunucu odası bulunmaktadır. İlgili odada } 1 \text { kabinet ve kabinet içinde } 2 \text { adet fiziksel sunucu barın- } \\
\text { maktadır. Oda içerisinde } 1 \text { adet } 7 / 2418 \text { derecede çalışan standart bir klima mevcuttur. Klima inventer değildir. } \\
\text { Bu sunucularda; web sitesi dosyaları, kütüphane ve tez savunma programları mevcuttur. Sunucularda sanallaş- } \\
\text { tırma yapılmıştır. }\end{array}$ \\
\hline Y12 & $\begin{array}{l}\text { Sunucu odalarının bulunduğu yer zemin katta yer almaktadır. Yerin belirlenmesi için özel bir politika güdülme- } \\
\text { miştir. Kabinetler cama yakındır ve odada izolasyon yapılmamıştır. }\end{array}$ \\
\hline Y13 & Web sitesi barındırma, dosya paylaşım, çeşitli intranet uygulamaları için kullanılmaktadır. \\
\hline Y14 & $\begin{array}{l}\text { Yetkililer bulut bilişim hakkında fikir sahibi olmasına rağmen, bulut teknolojisinin avantajlarından faydalanma- } \\
\text { maktadır. }\end{array}$ \\
\hline Y15 & $\begin{array}{l}\text { Sunucuların buluta taşınmasında güvenlik kaygısı vardır. Öğrenci ve personel ile ilgili kişisel ve önemli bilgilerin } \\
\text { mevcut olması kaygının temel nedenidir. }\end{array}$ \\
\hline
\end{tabular}




\subsubsection{Kullanıcı Görüşme Formu'nun Değerlendirilmesi}

DEÜSBE insan kaynakları biriminden alınan 01.09.2015 verisine göre; kurumda toplam 28 idari ve 11 akademik personel bulunmaktadır. KGF, iş yerinde kendine ait bilgisayarı olan 33 personele uygulanmıştır. Formun uygulanmadığı personel, resmi izinli olan personellerdir. KGF'nin demografik dağılımında; \%85'lik bir katılım söz konusudur. Katılımcıların \%54.5'i kadın, \%45.5'i erkektir. Katılımcılar eğitim düzeyi; \%15.2 lise ve altı, \%24,2'si ön lisans, \%33.3'ü lisans, \%12.1'i yüksek lisans ve \%15.2'si doktora düzeyindedir. Ayrıca katılımcıların kadro durumu \%69.7'i idari personel ve \%30.3'u ise akademik personeldir. Katılımcıların yaş dağılımında; \%9.1'i 28 altı, \%27.3'ü 28-35 arası, \%33.3'ü 36-45 ve \%30.3'ü 45 üzeri şeklindedir. Katılımcıların hizmet yılı dağılımı ise; \%27.3'ü 5 ve altı, \%12.1'i 5-10, \%6.1'i 11$15, \% 18.2$ 'si 16-20 ve \%36.4'ü ise 20 üzeridir.

Avrupamak Büro Makineleri firmasından 19.04.2016'de bir takım maliyetler alınmıştır (Tablo 7 ve Tablo 8). Bu veriler ile kişisel ve ofis tipi kullanım kıyaslandığında; ofis tipi bir ürünün kişisel kullanım ürününe göre yaklaşık 2.6 kat, tek yüz baskıda ve 3.1 kat, arkalı önlü baskıda maliyet avantajı sağladığı görülmektedir.

Tablo 7: HP 1010 ve Ricoh MP 4000 için Maliyet Listeleri

\begin{tabular}{|l|c|c|c|c|c|c|}
\hline Model & $\begin{array}{c}\text { Kişisel/ } \\
\text { Ofis }\end{array}$ & $\begin{array}{c}\text { Baskı } \\
\text { Sayısı }\end{array}$ & $\begin{array}{c}\text { 1 Paket/ 500 Sayfa } \\
\text { Kağıt }\end{array}$ & $\begin{array}{c}\text { Orijinal } \\
\text { Toner }\end{array}$ & Cihaz Maliyeti & Baskı Ömrü \\
\hline HP 1010 & Kişisel & 2.000 & $8 \mathrm{TL}$ & $150 \mathrm{TL}$ & $284 \mathrm{TL}$ & 50.000 \\
\hline Ricoh MP 4000 & Ofis & 30.000 & $8 \mathrm{TL}$ & $241 \mathrm{TL}$ & $12.864 \mathrm{TL}$ & 1.000 .000 \\
\hline
\end{tabular}

Tablo 8: HP 2010 ve Ricoh MP4000 Sayfa Başı Baskı Maliyetleri

\begin{tabular}{|l|c|c|}
\hline Maliyetler (A4 Kağıt) & HP 1010 & Ricoh MP4000 \\
\hline 1 Sayfa kağıt maliyeti & 1.6 Kuruş & 1.6 Kuruş \\
\hline 1 Sayfa için toner maliyeti & 7.5 Kuruş & 0.8 Kuruş \\
\hline 1 Sayfa için cihaz maliyeti & 0.57 Kuruş & 1.29 Kuruş \\
\hline 1 Sayfa için tek yüz baskı maliyeti & 9.67 Kuruş & 3.69 Kuruş \\
\hline 1 Sayfa için arkalı önlü baskı maliyeti & 17.74 Kuruş & 5.78 Kuruş \\
\hline 2 Sayfa için tek yüze baskı maliyeti & 19.34 Kuruş & 7.38 Kuruş \\
\hline
\end{tabular}

Kullanıcı alışkanlıkları üzerine sorulan sorulara verilen cevaplar, sırasıyla aşağıdaki şekiller ve tablo üzerinde gösterilmektedir. Kullanıcılar günde ortalama 50 çıktı almaktadır. Arkalı önlü çıktı ile tek yüz çıktı arasında \% 9 maliyet avantajı (Tablo 8) söz konusudur. Kullanıcıların toplam tüketim dikkate alındığında, \%72.73'ünün (Şekil 2) tek yüz baskı almaktadır.

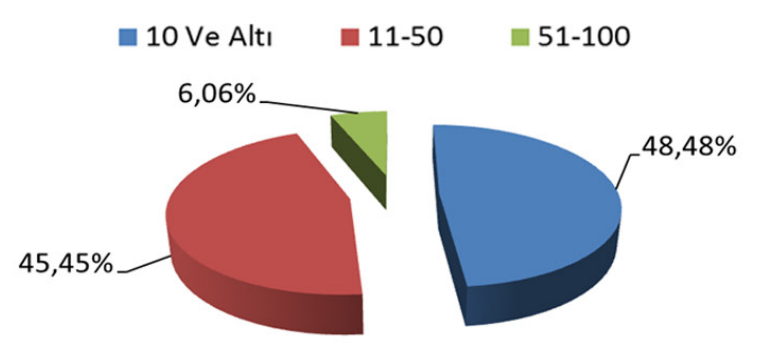

Günde Kaç Sayfa Çıktı Alırsınız?

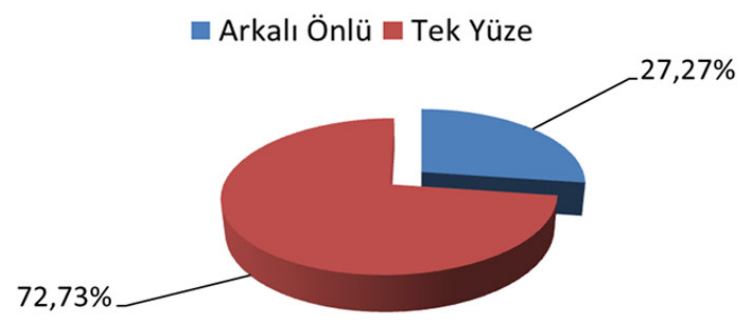

Çıktı Alırken Arkalı Önlü Mü Alırsınız?

Şekil 2: Çıktı Alma Alışkanlığı 
Kullanılan yazıcıların hafta içi ve iş çıkışında kapatılması ile ilgili sorulara verilen cevaplarda, kullanıcıların \% 45.45'i iş çıkışında yazıcılarını kapatmamaktadır (Şekil 3).

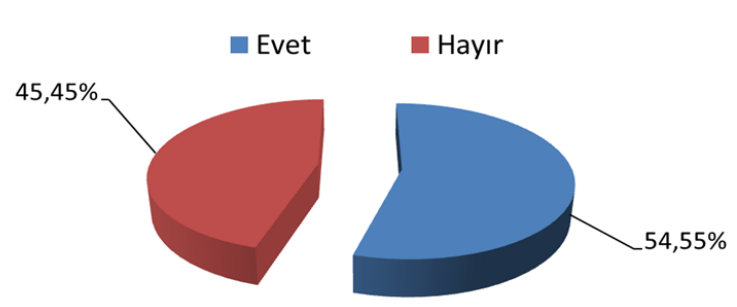

Kullandığınız Yazıcıları İş Çıkışında Kapatır Mısınız?

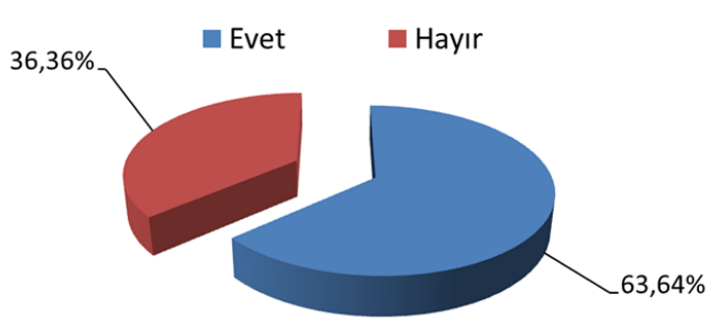

Yazıcılarınız Hafta Sonları Kapalı Durumda Mıdır?

Şekil 3: Yazıcı Kullanım Alışkanlığı

Kurumda kullanılan Triumph Adler 256i yazıcı $0.04 \mathrm{KW}$ enerji tüketmektedir. Personelin mesaiden 17:00'de çıktığı ve 9:00'da başladığı düşünüldüğünde, geçen zaman 16 saattir. Kişilerin unutkanlığının kuruma maliyeti $0.04 \mathrm{KW} \times 16$ saat $=0.64 \mathrm{KWh}$ ve 0.20 TL'dir. Yazıcıların hafta sonu açık kalma durumu için verilen cevaba, \%36.4 oranında kullanıcı, hafta sonu yazıcıyı kapatmadığını ifade etmiştir (Şekil 3). Cuma 17:00 mesai bitiminden, pazartesi 9:00'da başlanılan mesai arasında geçen zaman 64 saattir. Bu sürede
$0.04 \mathrm{KW} \times 64$ saat $=2.56 \mathrm{KWh}$ tüketim ve maliyet 2.56 x $0.32=0.82$ TL'dir.

Kullanıcıların \%48.5'i öğle yemeğine çıkarken hiçbir şey yapmadan çıktığını belirtmiştir (Şekil 4). Samsung syncmaster 932 Gw monitör ile bilgisayar kasası saatte $0.1 \mathrm{KW}$ (Tablo 4) güç tüketmektedir. Kuruma bir personelin öğle arasında bilgisayarını 1 saat açık bırakmasının maliyeti 3.2 kuruştur. Küçük molalara çıkarken bu oran \%66.7'ye çıkmıştır (Şekil 4). Bilgisayarının 30 dakikalık molada açık kalmasının maliyeti 1.6 kuruştur.

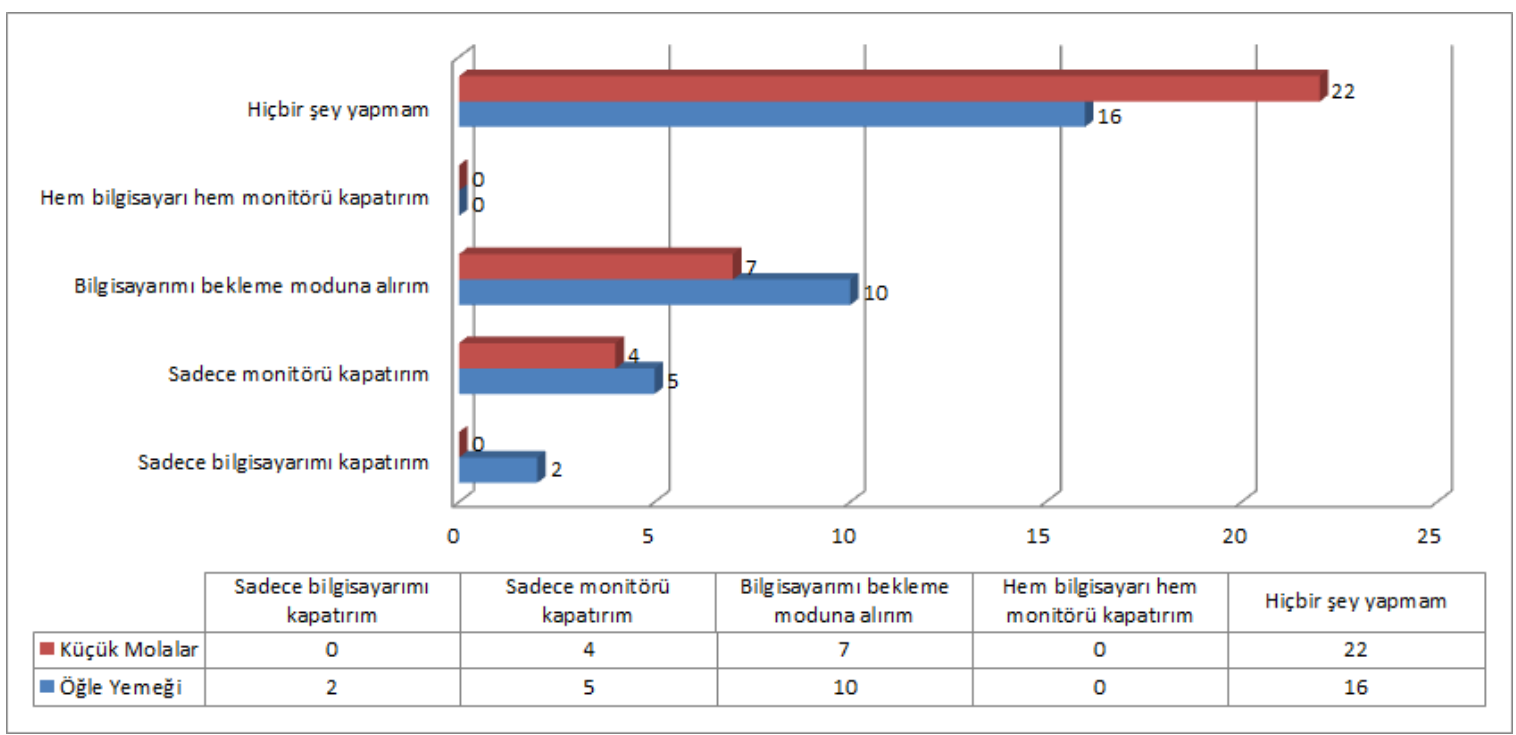

Şekil 4: Kullanıcıların Molaya Çıkarken Bilgisayar Kullanım Alışkanlığı

Kullanıcıların bilgisayarlarını düşük enerji $\% 51.5^{\prime} \mathrm{i}$ modları önemsemediklerini ve kullanıcıların tüketiminde kullanımı ile ilgili soruya kullanıcıların sadece \%15.2'si bu modları her zaman önemsediğini 
belirtmiştir (Şekil 4). Kullanıcıların küçük molalarda veya öğle aralarında bilgisayarlarını uyku moduna almaları, güç tüketimini \%73 oranında azaltmaktadır (Tablo 4).

Kullanıcıların bilgisayar kullanım süreleri incelendiğinde (Şekil 5), kullanıcıların \%81.8'nin 10
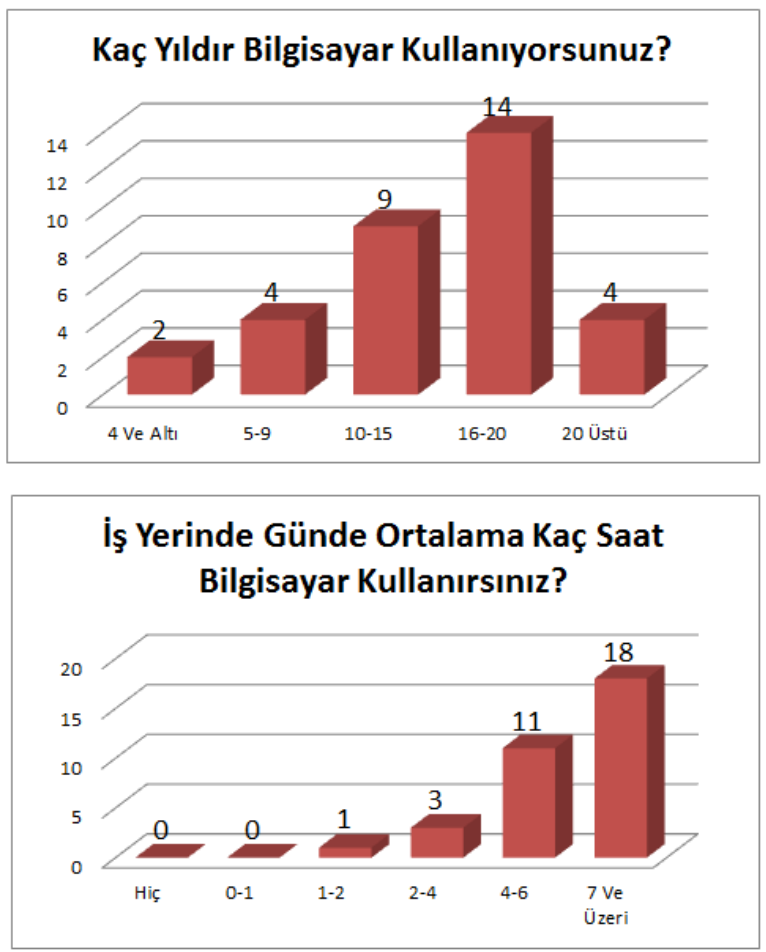

Şekil 5: Yıllık-Günlük Bilgisayar Kullanımı ve Kullanıcı Alışkanlıkları

Bir personelin yılda sadece 20 iş günü izin aldığını, haftada 5 gün çalıştığını ve günde 4 saat bilgisayar kullandığını düşündüğümüzde 5 (haftalık iş günü) $x$ 52 (yıllık hafta sayısı) x 4 (yaklaşık günlük kullanım) x $0.1 \mathrm{KW}$ (kasa ve monitörün haradığı güç) $\times 0.32$ (1 KWh'ın TL karşlığı) = 33,28TL, bir personelin kuruma yansıyan yıllık bilgisayar kullanım maliyetidir.

Aynı personelin hiçbir şekilde bilgisayarını kapatmadığı ve kullanım modlarını önemsemeden bilgisayarını kullandığını düşündüğümüzde, kuruma yansıyan maliyeti 365 (yıldaki gün sayısı) x 24 saat (1 gün) x 0.1 KW (kasa ve monitörün haradığı güç) $x$ 0.32 (1 KWh'ın TL karşlı̆ı) = 280,32 TL'dir. Kullanıcının dikkatsizkullanımı, kuruma olması gereken maliyetten yaklaşık 7.4 kat daha fazla maliyet oluşturmaktadır. ve üzeri yıllarda bilgisayar kullandığı görülmektedir. Kullanıcıların gün içinde bilgisayar kullanımları ile ilgili soruya 4-6 saat arasında \%33.3 ve \%54.5'nin 7 ve üzeri bilgisayar kullandıklarını, ifade etmişlerdir. Kullanıcıların $\% 54.5^{\prime} \mathrm{i} 7$ ve üzeri saat monitörlerinin açık kaldığını ifade etmiştir. 4 ve üzeri saat monitörün açık kaldığını ifade eden kullanıcı oranı \%87.8'dir.

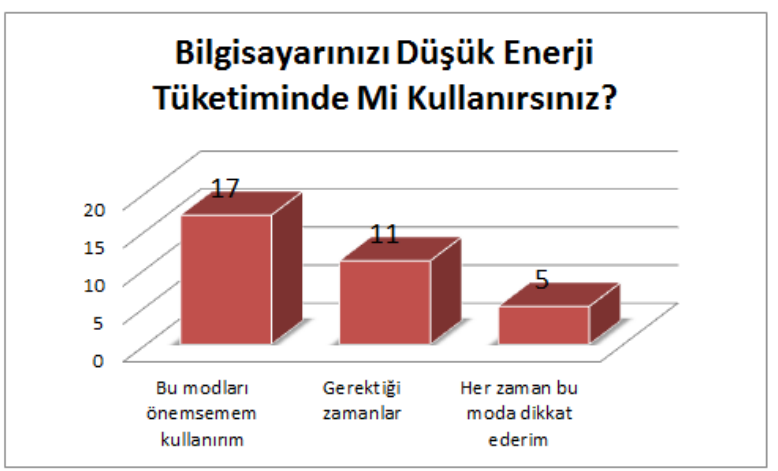

\section{İş Yerinde Günde Ortalama Kaç Saat Monitörünüz Açık Kalmaktadır?}

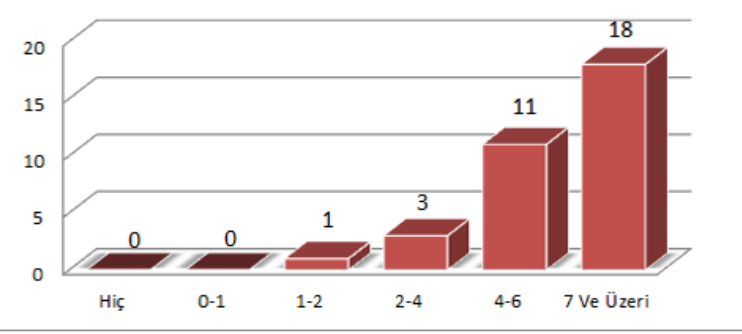

Kullanıcıların bu noktada yaklaşık $\% 51.5^{\prime}$ inin modu önemsemeden kullanması, personel başına 247,04 TL yıllık ekstra maliyet oluşturmakta ve yürütlecek enerji polikasını maliyet açııından anlamlı kılmaktadır.

Kullanıcılara, yeşil bilişim konusunda bilgilendirme yapıldıktan sonra; kendilerini, işyeri arkadaşlarını ve kurumlarını değerlendirmeleri istenmiştir. Kendilerine 6 puan, iş arkadaşlarına 5.5 puan ve kurumlarına 5.7 puan vermişlerdir. İlgili puan aralığı 1(kötü)-10(iyi) arasında değişmekte ve kullanıııların yeşil bilişim konusunda 3 boyuttaki değerlendirmede ortalama değer verdikleri gözlenmiştir (Tablo 9). Kişiler bu değerlendirme ile; kendilerini, iş arkadaşlarını ve kurumu iyileşmeye açık görmektedir. 
Tablo 9: Değerlendirme Boyutu Cevapları

\section{C1, C2 ve C3 Tanımları}

C1:Kendinize Yeşil Bilişim Konusunda Bir Puan Verir Misiniz?

C2: İş Arkadaşlarınızın Yeşil Bilişim Konusunda Bir Puan Verir Misiniz?

C3:Kurumunuza Yeşil Bilişim Konusunda Bir Puan Verir Misiniz?

\begin{tabular}{|c|c|c|c|}
\hline & C1 & C2 & C3 \\
\hline Katılım Sayısı & 33 & 33 & 33 \\
\hline Ortalama Değer & 6.00 & 5.48 & 5.70 \\
\hline Standart Sapma & 2.17 & 1.87 & 2.34 \\
\hline Minimum Değer & 1.00 & 2.00 & 1.00 \\
\hline Maksimum Değer & 10.00 & 9.00 & 10.00 \\
\hline
\end{tabular}

\section{SONUÇ VE ÖNERILER}

Çalışmada örnek bir kamu birimi üzerinde yeşil bilgi işlem yaklaşımıyla bir inceleme yapılmış ve kurumun içinde bulunduğu mevcut durum analiz ediliştir. Kurumun kullandığı bilişim cihazlarının; enerji tüketimi, satın alınması, kullanıcıların cihaz kullanım alışkanlıkları ve alışkanlıkların kuruma yansıttığı maliyeti ortaya koymaktadır. Yürütülen süreçler, iyileştirme adına önemli bir potansiyele sahiptir. Kurumun yürütmüş olduğu enerji politikasının olmaması ve bilişim ürünlerinin tasarruflu kullanılmasına dönük yaklaşımlardan habersiz olması, kamu kurumları içinde bu bağlamda bir fırsatın olduğunun göstergesidir. Bulgular bölümünde, bu durumun önemini ortaya koyabilmek için, ürünlerin enerji tüketim maliyetleri ile kulanıcı alışkanlıklarına bağlı maliyetler ortaya konulmuştur. Çalışma, yeşil bilişim konusunda bireysel ve örgütsel farkındalığı artırma; yeşil bilişim gibi önemli bir konuyu literatür çerçevesinde ele alarak, gerçekleştirilen formlar ve yapılan ölçümler ile somut sonuçlara ulaşması adına önem taşımaktadır. Yapılan literatür incelemesinde, kamu krumlarını yeşil bilişim açısından bu boyutta analiz eden, kullanıcı alışkanlıklarına bağlı somut sonuçlar ortaya koyan, çalışmaya rastlanılmamıştır.

KGF'den sağlanan verilerde; kullanıcıların \%48.5'i öğle yemeğine çıkarken, \%66.7'sinin küçük molalara çıkarken hiçbir şey yapmam şeklinde cevap vermesi, kurum içindeki bilgi işlem sorumlularının önemini ve politika gereksinmini ortaya koymaktadır. Kullanıcılar, tahsis edilen cihazların ayarlarıyla ilgili bir faaliyette bulunmadıklarını belirtmişlerdir. Bilgi işlem sorumluları, kurumdaki bilgisayarları, kullanıcı hizmetlerine açmadan önce, bekleme moduna geçiş, düşük enerji modunda kullanım gibi ayarlamaları yapmaları, kurum için önemli ölçüde enerji tasarrufu sağlayabilir (Tablo 4).

Kullanıcıların, \%51.5'inin, bilgisayarlarınızı düşük enerji tüketiminde kullanır mısınız sorusuna, yanıtın bu modları önemsemem kullanırım, cevabını vermesi, kurum içinde bir enerji politikası güdülmediğinin, farkındalık oluşturulması gereğinin bir başka göstergesidir. Kullanıcının bilişim cihazlarını dikkatsiz kullanımı, kuruma olması gereken maliyetten yaklaşık 7.4 kat daha fazla maliyet oluşturabilmektedir. Kurum yetkili görüşmelerinden edinilen izlenim doğrultusunda, bir enerji politikasının olmadığı, satın alma süreçlerinin marka unsurları baz alınarak gerçekleştiği, enerji tüketim miktarlarının dikkate alınmadığı söylenebilir.

Envanterlerin oluşturulması sırasında kurum içerisindeki odalarda, kendine ait bilgisayarı olan her personelin kendine ait yazıcısı olması dikkat çekici unsurdur. Bu durum, kurum satın alma politikasında ve teknolojinin etkin kullanımında, bir problemin göstergesidir. Tablo 8 ve Tablo 9 verileri incelendiğinde; kişiye özgü yazıcılar, ofis tipi yazıcılara göre, daha düşük amortisman giderlerine sahip olmalarına rağmen, sayfa başı baskı maliyetlerinde dezavantajlıdır. Detaylandıracak olursak; ofis tipi bir ürünün kişisel kullanım ürününe göre yaklaşık 2.6 kat tek yüz baskıda ve 3.1 kat arkalı önlü baskıda maliyet avantajı sağladığı görülmektedir. Aynı zamanda ofis tipi kullanımlarda, kağıt sarfiyatını, toner giderlerini, servis maliyetlerini denetlemek ve kontrol altına almak çok daha kolay olacaktır. Kullanıcıların çıktı alırken \%72.7'sinin tek yüze çıktı almayı tercih etmesi, kurum içindeki yazıcı sayısının yanında kağıt sarfiyatında bir problemin göstergesidir. 
Tüm bu sonuçlar ışığında, kurum içi enerji tasarrufuna yönelik hedeflerin geliştirilmesi, sistematik ölçümler ile bu hedeflere ulaşma düzeyinin izlenmesi, kurum stratejik planı içerisinde enerjinin bir kalem olarak alınması gereği ortadadır. Yeşil bilişim, bilişim teknolojisi ürünlerinin üretiminden kullanımına ve yaşam ömrünün bitiminden sonra tekrar doğaya zarar vermeden dönüştürülmesine kadar birçok süreci kapsamaktadır. Bu bağlamda yeşil bir bilgi işleme dönük öneriler sırasıyla kullanıcı ve kurum odaklı öneriler şeklinde sıralanacaktır.

Kullanıcı odaklı olarak aşağıdaki öneriler verilebilir:

- Bilgisayar, monitör gibi cihazlar; yemek molaları, küçük molalar, toplantı araları, özetle cihazların kullanımına gerek olmadığında kapatılabilir.

- Kullanıcılar, bilişim teknolojilerini, düşük enerji tüketiminde kullanmaya özen göstermelidir. Eğer bu modların nasıl kullanılacağı bilinmiyorsa, bilgi işlem sorumlularından yardım alınabilir.

- Kullanıcılar, resmi yazışmaları haricinde çıktı alırken, daha önce kullanılmış bir yüzü boş kâğıtları kullanabilir. Aynı zamanda sadece çıktı alınacağı zaman yazıcının çalıştırılması önerilebilir.

- Kullanıcılara, hafta mesaisinin son günü, bilgisayar ve kullandıkları diğer cihazların hafta sonu açık kalmayacak şekilde, izinlerine çıkmaları önerilir.

- Laboratuvar sorumluları, bilgisayar kullanacılarının işlerinin bitiminde bilgisayarları kapatmaları konusunda uyarabilir. Açık monitör ve bilgisayarın olup olmadığı konusunda gün içinde kontrollerde bulunabilir.

- Kişisel maillerimizde, kâğıt sarfiyatı, karbon salınımı, enerji sarfiyatıyla ilgili dipnotlar yazılarak diğer insanlar üzerinde farkındalık oluşturulabilir.

- Enerji sarfiyatıyla ilgili bilgi düzeyimizi, kişisel ilgi alanı haline getirerek, çevremizdeki diğer insanlar ile paylaşabilir; sadece iş yerinde değil, hayatımızın her alanında enerji tasarrufu ve çevresel etkimizi minimize eden bir yaklaşımı benimsenebilir.

- Bilişim araçları ile ilgili bilgi işlem sorumluları, laboratuvarlara, toplantı salonlarına ve dersliklere, "işimiz bittiğinde lütfen kapatalım" benzeri uyarı notları veya afişler asabilir.
Kurum odaklı olarak aşağıdaki öneriler verilebilir:

- Kurum içi enerji politikası oluşturulabilir ve kullanılan cihazların enerji tüketimleri, maliyetleri ve çevreye verdiği zararlar konusunda personele eğitim verilebilir.

- Kurum içi görev dağılımında, enerji tüketim ve tüketimin kontrolü konusunda ek bir görev yer alabilir. İlgili kişi elde edilen verileri, diğer personellere ulaştırabilir, iyileştirme faaliyetler konusunda bilgilendirme yapabilir ve enerjinin daha tasarruflu kullanımı ve çevreye verdiğimiz olumsuz etkileri içeren bilgilendirici toplu mailler gönderebilir.

- Kurum, evrak yönetim sistemi gibi kurum içinde kâğıt sarfiyatını önemli ölçüde azaltan yazılımları kullanabilir.

- Bilişim teknolojilerinin kendi karbon ayakizinden yedi kat karbon ayak izini azaltma potansiyeli vardır. Yetkililer, teknolojinin kullanım ile etkinleştirilebilecek süreçler için ihtiyaç analizi yapabilir.

- Hemen hemen tüm kamu kurumlarında bir sunucu odası mevcuttur. Bu noktada sunucu odalarının tercihi ve oda içerisindeki iklimlendirme araçlarının tercihi ve gereksinimi özenli yapılabilir.

- Kurumlar ihtiyaçlarını, bulut hizmeti giderebilir ve bulut hizmetinin, gelişmiş performans, düşük yazılım maliyeti, ayarlanabilir kapasite, erişim kolaylığı, verimlilik, sabit yatırım maliyetinin olmaması, anında güncelleme, sınırsız depolama kapasitesi, artırılmış veri güvenliği, işletim sistemleri arasında uyum ile çevre dostu olması gibi avantajlarından faydalanabilir.

- Kurum personeli çıktı alırken daha önce kullanılmış bir yüzü boş olan kâğıtları kullanması özendirilebilir. Kurumda kişiye özgü yazıcılar yerine oda hizmetinde veya kurumun hizmetinde yazıcı kullanımı tercih edilebilir. Bu şekilde kâğıt tüketimi daha kolay kontrol altına alınabilir.

- Performansı düşmüş, teknolojisinin gerisinde kalmış teknolojik cihazlar daha fazla enerji tüketebilir. Bu tür cihazlar, kullanımın daha az olduğu yerlerde tercih edilebiir.

- Kurum içinde yeşil politikalar yürütülebilir. Örneğin; bilgisayarlara, oda kapılarına, panolara, 
etkin enerji kullanımı ile ilgili notlar asılarak, farkındalık oluşturulabilir.

- Yetkililer, gece bekçisi ve müstahdemlere, kullanılmayan yazıcı, monitör, bilgisayar gibi cihazları kapatmaları telkin edilebilir.

- Bilişim teknolojisi cihazlarını içine alan kurum içi bir geri dönüşüm politikası oluşturulabilir.
Kurum stratejik planında, enerji giderleri için yıllık tasarruf hedefleri yer alabilir ve bu hedefler izlemeye alınabilir.

- T.C. Enerji ve Tabi Kaynaklar Bakanlığı tarafından yürütülen enerji verimliliği çalışmalarının takibi önerilebilir.

\section{KAYNAKLAR}

Aggarwal, S., Garg, M. ve Kumar, P. (2012) "Green Computing is Smart Computing - A Survey" International Journal of Emerging Technology and Advanced Engineering, 2(2):297-303. Akın, B. ve Kuru, A. (2011) “Elektrikli Ve Elektronik Atıkların (E-Atık) Zararları, Yönetimi Ve Türkiyedeki Uygulamalarının Değerlendirilmesi", İstanbu Aydın Üniversitesi Dergisi, 2(12):1-12. Andreopoulou, S.Z.(2012) "Green Informatics: ICT for Green and Sustainability".Agricultural Informatics, 3(2):1-8.

Bengtsson, F. ve Agerfalk, J.P. (2011) “Information Technology as a Change Actant in Sustainability Innovation: Insights from Uppsala" Journal of Strategic Information Systems, 20(2011):96-112.

Bose, R. ve Luo, X. (2011) "Integrative Framework For Assessing Firms' Potential to Undertake Green IT Initiatives Via Virtualization-A Theoretical Perspective" Journal of Strategic Information Systems, 20(2011):3854.

Bölgesel Çevre Merkezi'nin Sürdürülebilir Kalkınma İçin Bilişim Raporu (2013)“Bilgi ve İletişim Teknolojileri Sektörünün Türkiyesde Düşük Karbonlu Topluma Geçişi ve Sürdürülebilir Ekonomik Büyümedeki Rolü" http://www.vodafone.com.tr/VodafoneHakkinda/ Surdurulebilir_Kalkinma_icin_Bilisim_Raporu.pdf (24.02.2016).

BTK (2010). BTK Yeşil Bilişim Raporu. Ankara: Bilgi Teknolojileri ve İletişim Kurumu.

Chakraborty, P., Bhattacharyya, D., Nargiza, S.Y. ve Bedajna, S.(2009) "Green computing: Practice of Efficient and Eco-Friendly Computing Resources" International Journal of Grid and Distributed Computing, 2(3):33-38.

Chou, C.D., (2013) "Risk Identification in Green IT Practice" Computer Standards \& Interfaces, 35(2013):231-237.

Chou, C.D. ve Chou, Y.A. (2012) "Awareness of Green IT and Its Value Model" Computer Standards \& Interfaces, 34(2012):447-451.
Çetin, H. ve Akgün, A. (2015) “Yeşil Bilişim Teknolojileri Bağlamında Sanallaştırılmış ve Klasik Sistemlerin Karşılaştırılması" Uluslararası Alanya İşletme Fakültesi Dergisi, 7(2):131-142.

Dao, V., Langella, I. ve Carbo, J.(2011) "From Green to Sustainability: Information Technology and an Integratedsustainability Framework" Journal of Strategic Information Systems, 20(2011):63-79.

Elliot, S. ve Binney, D. (2008) "Environmentally Sustainable ICT: Developing Corporate Capabilities and an Industry Relevant IS Research Agenda" Proceedings of PACIS 2008, 4-7 Temmuz, Suzhou, China.

Hart, L.S. ve Ahuja, G. (1996) “Does It Pay To Be Green? An Empirical Examination Of The Relationship Between Emission Reduction And Firm Performance". Business Strategy and the Environment, 5: 30-37

Hepkul, A. ve Polatoğlu, K.V. (2013) “Türkiye'de Kurumsal Sosyal Sorumluluk Olarak E-Atıkların Bertarafı" Social Business @ Anadolu International Conference, 30-31 May 2013 Eskişehir, Turkey. s.169173.

Jenkin, A.T., Webster, J. ve McShane, L. (2011) "An Agenda for 'Green' Information Technology and Systems Research" Information and Organization, 21(2011):17-40.

Kaya, M. ve Sözeri A. (2007)“Electronic Waste (E-Waste) Recycling/Recovery System" 13th International Energy, Cogeneration And Environmental Technologies Conference \& Exhibition, 30-31 May 2007, İstanbul.

Molla, A., Cooper, A.V. ve Pittayachawan, S. (2009) “IT and Eco-sustainability: Developing and Validating a Green IT Readiness Model" ICIS 2009 Proceedings, Paper 141.

Özdemir, A., Naralan, A. ve Çam, A. (2015) "Organizasyonlarda Maliyet Tasarrufu Sağlayan Etkin Bir Strateji: Sanallaştırma Teknolojisi", Küresel Iktisat ve İşletme Çalışmaları Dergisi, 4(8):45-56. 
Shinde, S., Nalawade, S. ve Nalawade, A. (2013) "Green Computing: Go Green and Save Energy" International Journal of Advanced Research in Computer Science and Software Engineering, 3(7):1033-1037.

Dünya Gazetesi (2010) "Teknoloji Atıkları: Değerli mi? Tehlikeli mi?". http://www.dunya.com/isletmeyonetim/teknoloji-atiklari-degerli-mi-tehlikeli-mi101428h.htm (24.02.2016).

Tema Vakfı (2015) "2050'de Üç Tane Dünyaya İhtiyacımız Olacak!" http://www.tema.org.tr/ web_14966-2_1/entitialfocus.aspx?primary_id= $1458 \&$ target $=$ categorial $1 \&$ type $=2 \&$ detail $=$ single (24.02.2016).
Türkiye'nin Ekolojik Ayak İzi (2012) “Türkiye'nin Ekolojik Ayak İzi Raporu" http://awsassets.wwftr. panda.org/downloads/turkiyenin_ekolojik_ayak_izi_ raporu.pdf (24.02.2016).

Yazıcı, E.Y. ve Deveci, H. (2011) "Geleceğin Madenleri: E-atıklar"Türkiye 22. Uluslararası Madencilik Kongresi ve Sergisi 11-13 Mayıs 2011, ANKARA

Zhu, Q. ve Cote, R. (2004) "Integrating Green Supply Chain Management Into An Embryonic Eco-Industrial Development: A Case Study Of The Guitang Group", Journal of Cleaner Production, 12(2004):1025-1035. 